\title{
DISTURBED EATING ATTITUDES AMONG MALE AND FEMALE UNIVERSITY STUDENTS
}

\author{
Nida ${ }^{*}$ \\ Saima Masoom $\mathrm{Ali}^{* *}$
}

\begin{abstract}
Present study compared disturbed eating attitudes among male and female university students. For which it was postulated that female university students would have more disturbed eating attitudes as compare to male students. For that reason 200 males and 200 female university students from various universities of Karachi were incorporated in the study. Their age ranged from 19 to 25. Participants after verbal and written covenant from the heads of their institution were asked to fill the respondents' profile form to gather the participant's demographic information, followed by Eating Attitude Test (EAT-26) which was used to know ones disturbed eating ways. For statistical evaluation t-test was applied, which specified that male university students experience more disturbed eating attitudes compare to female learners. This clears that distressed eating attempts are not limited to females, but is now affecting males as well. Thus to avert its budding prevalence, teaching institutions should supervise its amassed risks in their students and stimulate them to healthy lines of eating.
\end{abstract}

Keywords: Disturbed eating attitude, university students, male and female

\section{Introduction}

Eating attitude can simply be defined as person's behavior, thought and feeling to nutritive stuff. ${ }^{1}$ Whereas, disturbed eating approach is defined as an eating behavior that does not permit the diagnosis of eating disorder. ${ }^{2}$ Further with regards to carrying disruptive eating practices, variety of unhealthy eating styles may be listed including eating to fill the emotional emptiness, habitual eating actions, external style of eating (you see it, you eat it), eating for pleasure, purging out, depending self completely on pills. ${ }^{3}$

Problematic eating attempts together in undergraduate male and female population nowadays have become an imperative debate world widely. ${ }^{4}$ In a search there was (75\%)

\footnotetext{
* Nida, Research Scholar, Department of Psychology, University of Karachi.

${ }^{* *}$ Saima Masoom Ali, Ph.D. Assistant Professor, Department of Psychology, University of Karachi.

${ }_{1}^{1}$ Alvarenga, "Disordered Eating Attitude". Percept Mot Skills, 110(2), 2010, 379-395.

${ }^{2}$ Tsai, "Survey on eating related thoughts, behaviors and dietary intake in female undergraduates in Taiwan, Asia Pacific Journal of Clinical Nutrition, 20, 2011:196-205.

${ }^{3}$ Chan MF, Ho A, Day MC. Investigating the knowledge, attitudes and practice patterns of operating room staff towards standard and transmission-based precautions: results of a cluster analysis. J Clin Nurs. 2008 17(8), 2015:1051-1062. doi: 10.1111/j.1365-2702.2007.01998.

${ }^{4}$ Madanat, Lindsay and Campbell, "Young urban women and the nutrition transition in Jordan", Public Health Nutrition,14(4), 2011, 599-604.4
} 
of unsafe eating approaches in both male and female student masses recorded. ${ }^{5}$ Whereas some publicized about (50 to $75 \%$ ) of undergraduate females indulged in severe starving than males. ${ }^{6}$ Likewise in Jew undergraduates a complex degree of irregular-eating was also found at $(60 \%){ }^{7}$ Equivalent results exhibited by Turkish undergraduates. ${ }^{8}$ The rise of problematic eating patterns also reported in the female intellects of Hong-Kong. ${ }^{9}$ Detection on female university learners of Japan brought in to knowledge that around $75 \%$ of them were involved in high practice of unhealthy eating than males. ${ }^{10}$ A study in Brazil documented $76 \%$ for females, practicing problematic eating approaches. ${ }^{11} \mathrm{~A}$ search in UK identified $40 \%$ of males and $75 \%$ of females; $60 \%$ of females and $30 \%$ of males in Canada; and in Lebanon $80 \%$ of females, and $75 \%$ of males as practicing faulty eating approaches. ${ }^{12,13,14}$

Further researches have revealed body mass, and weight concerns; dissatisfaction with current body, depression, anxiety, stress and social pressures as the common facilitating factors of disturbed eating attitudes among university going students. ${ }^{15}$ Such as a search on undergraduates reported that those overrate their weight were nearly more likely to have bothered eating conducts than those who do not. ${ }^{16}$ Female students in another search having unhealthy rituals of eating evaluated themselves largely on their body-masses. ${ }^{17}$ By the same token a research on male university learners pointed out a strong association of body mass index with disturbed attempts of eating. ${ }^{18}$ Likewise in a study it was explored that a high percentage of Philippian female with concerns of body weight were practicing disruptive eating patterns. ${ }^{19}$ Similar results disclosed in $(17.11 \%)$ in Chines

\footnotetext{
${ }^{5}$ Brandsma and Lynn, "Eating disorders across the lifespan," Journal of Women \& Aging, 19(11), 2007, 155172.

${ }^{6}$ Trautmann and Julie, "Body Dissatisfaction, Bulimic symptoms, and clothing practices among males and females," The Journal of Psychology, 141(5), 2007, 485-498.

${ }^{7}$ Apter and Abu Shah, "Cultural effects on eating attitudes in Israeli sub-populations and hospitalized anorectics." Genetic, Social, and General Psychology Monographs, (2004):120, 83-99.

${ }^{8}$ Maor and Sayag, "Eating attitudes among youth," Turkish Medical Association Journal, 8(9), 2006, 627-629.

${ }^{9}$ Davis, "Body and self-esteem ratings as a prelude to dieting and exercise among Chinese men and women", International Journal of Eating Disorders, 23(4), 1998, 99-102.

${ }^{10}$ Sampei, Sigulem, Novo, Juliano and Colugnati,"Eating attitudes and body image in ethnic Japanese females". Journal of Eating Behavior, 85(2), 2009,122-128.

${ }^{11}$ Nunes, Barros, Anselmo, Camey and Mari, "Prevalence of abnormal eating behavior and inappropriate methods of weight control in young women from Brazil: a population based study". Eat Weight Disord, 2003, 8:100-6.

${ }^{12}$ Jina Tanton, Lorna, Dodd, Lorayne Woodfield and Mzwandile Mabhala, "Eating Behaviors of British University Students: A Cluster Analysis on a Neglected Issue", Advances in Preventive Medicine,Vol 2015, Article ID 639239, 8 pages, http://dx.doi.org/10.1155/2015/639239

${ }^{13}$ Starkey, Johnson-Down and Gray-Donald, "Food habits of Canadians: comparison of intakes in adults and adolescents to Canada's food guide to healthy eating", Can J Diet Pract, 62(2), 2001, 61-9.

${ }^{14}$ Yahia, Achkar, Abdallah and Rizk, "Eating habits and obesity among Lebanese university students",Nutrition Journal, 2008,7:32, https://doi.org/10.1186/1475-2891-7-32

${ }^{15}$ Human Nutrition, Nutrition Country Profile, Lebanon. http://www.fao.org/ag/agn/nutrition/lbn_en.stm

${ }^{16}$ Wharton and Christopher, "Weight loss practices and body weight perceptions among US university students," Journal of American College Health, 56(5), 2008, 579-584.

${ }^{17}$ Conley and Amanda, "Weight overestimation as an indicator of disordered eating behaviors among young women in the United States," International Journal of Eating Disorders, 40(5), 2007, 441-445.

${ }^{18}$ Thompson, "Body shape, eating disorders, and obesity in youth", (Washington DC, US, 2002)

${ }^{19}$ Lorenzo and Lavori, "Eating attitudes in high school students in the Philippines: A preliminary study," Journal of Eating Disorders, 7(3), 2002, 202-209.
} 
females. ${ }^{20}$ In another analysis on females despite of having normal body weight and size perceived themselves as bulgy and fat, and were involved in dieting and purging attempts. ${ }^{21}$ A review on university students reported link of dissatisfaction with self and feeling of dejection due to disruptive eating conducts. ${ }^{22}$ An investigation on undergraduates revealed high rate of depression in females who were mostly engaged in limiting or avoiding their meals and demanded to eat less, on the other hand high rate of depression found in males who were involve in over eating. ${ }^{23}$ A study in Arab also found (protein, carbohydrate, zinc and vitamins) at poorer level in 66\% of those university students who had disturbed patterns of eating and depression. ${ }^{24}$ Literature also shows significant association between depressing warning sign, stress and disturbed eating behaviors among university students. ${ }^{25}$ Literature on American undergraduates detected an impact of social stress to conserve the demanded body status through odd eating. ${ }^{26}$ As Western societies strongly believe to be fit and share inflexible reservation to body heaviness, which supports the continuous practice of disruptive eating attempts in these areas. ${ }^{27}$ It is clear that disturbed eating approaches have been turned out to be a serious matter and appear to last in upcoming years. Timely recognition of underlying factors associated with unhealthy attempts of eating may well help in making extended protective dealings. ${ }^{28}$

\section{Family, Peer and Media}

At times people eating attitudes are modified by their family or blood relatives. Various investigations have testified that parents have an extensive effect on their kids' eating behaviors. ${ }^{29}$ As a reason of which most of the people since their early age are prone to practice unhealthy eating attempts. ${ }^{30}$ However, these parental stresses on individual's eating attempts may have been reported due to limited understanding about food and its unhealthy attempts and societal pressures. ${ }^{31}$ A study on 379 university students

\footnotetext{
${ }^{20}$ Luo and Parish, "A population-based study of eating concerns among urban Chinese adults," Journal of Psychology, 2 (4), 2006, 333-345.

${ }^{21}$ Gustafson-Larson and Terry, "Weight-related behaviors and concerns in males and females," Journal of American Dietetic Association, 92(7), 1992, 818-822.

${ }^{22}$ Wilson and Jan, "The relative contributions of subjective and objective measures of body shape and size to body image and disordered eating in women," Journal of Molecular Biology, 2(3), 2005, 233-47.

${ }^{23}$ Coker and Austin, "The health and health care of adolescents". Health Science, (September, 2010): 31, 457477.

${ }^{24}$ Eapen, "Disordered eating attitudes and symptomatology among adolescent girls in the United Arab

Emirates," Eating Behaviors, (2006): 7, 53-60.

${ }^{25}$ Eapen, "Disordered eating attitudes and symptomatology among adolescent girls in the United Arab

Emirates," Eating Behaviors, (2006): 7, 53-60.

${ }^{26}$ Sharma, "Trends in the intake of ready-to-eat food among young students in Nepal," Journal of

Psychology, 16(5), 1998, 21-22.

${ }^{27}$ Mitchell and Eckert, "Scope and significance of eating disorders," Journal of Consulting and Clinical

Psychology, 55, 1987, 628-634.

${ }^{28}$ Lowery and Sarah, "Body image, self-esteem, and health-related behaviors among male and female first-year university students," Journal of Eating Disorders, 46(6), 2005, 612- 623.

${ }^{29} \mathrm{Kugu}$, Akyuz and Izgic, "The prevalence of eating disorders among university students and the relationship with some individual characteristics," Australian and New Zealand Journal of Psychiatry, 40(3), 2006 129-135.

${ }^{30}$ Philpott, "More than mere vanity," Guidance and Counseling, (1998):14, 28-39.

${ }^{31}$ Shin HS, Valente TW, Riggs NR, et al, "The interaction of social networks and child obesity prevention program effects: the pathways trial. Obesity". 2014;22(6):1520-1526. doi: 10.1002/oby.20731
} 
documented that students had no healthy eating attitudes because of the unhealthy eating practices throughout their life. ${ }^{32}$ Another search in Europe revealed the similar results in youngsters. ${ }^{33}$

Moreover peers also play a vital role in affecting one's eating attitudes; a study on South Asian undergraduates confirmed an unshakable effect of peer on their eating approaches. ${ }^{34}$ Moreover, another study found female students limiting their food for lunching in order to maintain relation with their peer in fear of being detached if ate more. ${ }^{35}$ Further in other findings association between peer exposure and unhealthy eating patterns also found significantly. Yet investigations on the quality of peer relations need to be examined. ${ }^{36}$

As Media is the important source of information. People are exposed to multiple information and pictures on television, magazines or the newspapers every day, which directly affect their lives, food choices and eating habits. ${ }^{37}$ Researches have also confirmed that in eastern countries disruptive eating patterns and body related concerns are highly spread through media. ${ }^{38}$ In a study of nonwestern university, scholars who were exposed to social media programs related to eating for short period of time and later exposed for long period of time. It was observed that the impact of long period exposure showed a major shift in their eating approaches and perception as they mostly have scored high on EAT-40 as compare to EAT-40 scores after being exposed to media for shorter duration. ${ }^{39}$ Further in a survey 30 percent of men and 70 percent of females believed that television screens and magazines affect their eating patterns negatively, and they feel worse about themselves after watching them. ${ }^{40}$

\section{Asian Studies}

From a viewpoint, bothered eating attempts turned out to be progressively typical in Singapore since early twentieth century. ${ }^{41}$ Numerous researches in Singapore have been

\footnotetext{
${ }^{32}$ Harrison ME, Norris ML, Obeid N, et al. Systematic review of the effects of family meal frequency on psychosocial outcomes in youth". Can Fam Physician. 2015;61(2):e96-e106.

${ }^{33}$ Velde SJ, Chin APaw MJ, De Bourdeaudhuij I, et al, "Parents and friends both matter: simultaneous and interactive influences of parents and friends on European schoolchildren's energy balance-related behaviours the ENERGY cross-sectional study. Int J Behav Nutr Phys Act. 2014;11:82. doi: 10.1186/1479-5868-11-82

${ }^{34}$ Ousley, "Fat talk among undregraduate students: How university students communicate regarding food and body weight, shape \& appearance," Journal of Eating Disorders, 16(8), 2008, 73-84.

${ }^{35}$ Hill and Franklin, "Peer pressure and dieting: Investigating the transmission of weight control," British Journal of Clinical Psychology,37(1), 1998, 3-13.

${ }^{36}$ Verstraeten R, Van Royen K, Ochoa-Avilés A, et al, "A conceptual framework for healthy eating behavior in Ecuadorian adolescents: a qualitative study". PLoS One. 2014;9(1):e87183. doi: 10.1371/journal.pone.0087183

${ }^{37}$ Vaida, "Prevalence of media exposure and its impact among urban students," The International Journal of Science, 2(3), 2013, 353-359.

${ }^{38}$ Tiggemann and Pickering, "Role of television in men and women's body dissatisfaction," International Journal of Eating Disorders," 20(2), 1996, 199-203.

${ }^{39}$ Harrison, "Ourselves, our bodies: media-ideal, self-discrepancies, and eating disorder symptomatology," Journal of Social and Clinical Psychology, 20(3), 2001, 289-323.

${ }^{40}$ Field and Camargo, "Peer, parent, and media influences on the development of weight concerns and frequent dieting among girls and boys," International Journal of Eating Disorders, 107(1), 2001, 54-60.

${ }^{41}$ Ong and Tsoi, "A clinical and psychosocial study of seven cases of anorexia nervosa in Singapore. Singapore Medical Journal, 23, 2000, 255-61.
} 
proposed that unhealthy eating attempts are getting mature the student population of high school, college and university. ${ }^{42}$ Similarly, an analysis on university population of India identified (14.8 percent) of partakers' carrying troubled eating attitude. ${ }^{43}$ Examinations led in Taiwan youth specified high marks on EAT-40 among (17.11 percent) of 1605 male learners of high school ${ }^{44}$, though infrequent, have been recognized in states of Japan such as in their periodical, proportions of unhealthy eating pattern in men were recorded round (2-3 percent), while for women it stretched from (5-10 percent). ${ }^{45}$ Another probe on Korean men $(\mathrm{N}=1249)$ and women $(\mathrm{N}=1813)$, described (8.5 percent) of them scored high on EAT-40. ${ }^{46}$ Likewise study in New Delhi, India revealed a high prevalence of faulty eating pattern in female health care students. ${ }^{47} \mathrm{~A}$ research in Uttar Pradesh, India also exposed problematic eating attempts and conducts in $(26.67 \%)$ young females of high school. ${ }^{48}$

\section{Pakistani Scenario of Unhealthy Approaches of Eating}

The youthful population of state like Pakistan is also getting affected of faulty eating attitudes. A study in this domain carried out in Lahore, Pakistan to evaluate the occurrence of disturbed eating attitudes in postgrad female medical learners, (17\%) of female students reported high scores on EAT scale. Exposure to Western values and norms and disappointment with own body shapes were identified as significant interpreters of disruptive eating attitudes. ${ }^{49}$ Similarly another study carried out on medical students of Karachi, Pakistan, $(87.9 \%)$ of females were found to be at high risk of eating disorder and males at $(12.1 \%){ }^{50}$

However there is still a scarcity of such studies in Pakistani populace and limited researches documented on the risk factors associated with unhealthy eating among Pakistani university students. Evaluation in this area may help in enhancing the prevention and treatment strategies. Thus in the light of above highlighted researches and writings, the present exploration was carried out with the purpose of estimating the differences among men and women university students with respect to their bothered

${ }^{42}$ Ung, "Eating disorders in Singapore: A Review". Singapore Medical Journal. 32, 2003, 19-24.

${ }^{43}$ Suresh and Fernandez,. "Eating disorders in India". Indian Journal of Psychiatry, 37(1),2000, 26-30

${ }^{44}$ Lee and Lock, Pathologic eating in Taiwan undergraduates, International Journal of Eating Disorder, 40(3), 2007, 227-31.

${ }^{45}$ Yamazaki, "Prevalence of eating disorders in a geographically defined area in Japan. International Journal of Eating Disorder, 28(2), 2000, 173-80.

${ }^{46}$ Rhee and Park, "Epidemiology of eating disorder symptoms in the Korean general population using a Korean version of the EAT": Eat Weight Disorder, (July 2006): 4, 153-61.

${ }^{47}$ Balhara, Yadav, Arya, Mathur and Kataria, "A cross-sectional study of body shape and eating attitude among Indian female healthcare students". International Journal of Psychiatry in Medicine, 43(4), 2012, 309-323 https://doi.org/10.2190/PM.43.4.b

${ }^{48}$ Upadhyah, Misra, Parchwani and Maheria, "Prevalence and risk factors for eating disorders in Indian adolescent females". National Journal of Physiology, Pharmacy \& Pharmacology, 4(2), 2014, 153-157 DOI: 10.5455/njppp.2014.4.041220131

${ }^{49}$ Suhail, K and Zaib-u-Nisa, "Prevalence of eating disorders in Pakistan: Relationship with depression and body shape". Eat Weight Disorder, 7(2), 2012, 131-8.

${ }^{50}$ Memon, Adil,Umar, Naeem and Adnan, "Eating disorders in medical students of Karachi, Pakistan". BMC Research Notes. 5, 2012, 84 doi: 10.1186/1756-0500-5-84 
approaches of eating. For which it was postulated that female university learners would have high levels of disturbed attitudes of eating at high level in contrast to male students.

\section{Method}

\section{Research participants}

A sample of two hundred male and two hundred female students from different universities of Karachi, were chosen after their consent. Mean age of study participants was $(22.5 \pm \mathrm{SD} 1.813)$

\section{Instruments}

Demographic Information Form

Demographic information included: gender, age, socio-economic position (upper, middle and lower), physical activities (participation in gym activities), BMI status (underweight, normal and overweight) and relationship status (single, engaged and married).

\section{Eating Attitude Test (EAT-26) ${ }^{51}$}

EAT-26 is not a diagnostic test based on 26 items; it is only used to measure the signs of problematic eating behaviors. Scores based on likert scale with ( $3=$ always, $2=$ usually, $1=$ often and 0 is for sometimes, rarely and never) whereas, there is a reverse scoring for the test item number 26 as: $(3=$ never, $2=$ rarely, $1=$ sometimes, and 0 is for often, usually and always). Test's total counts range (0-78). Scores at or above 20 directs a necessity of proficient support and lower than 20 put forward no proneness of bothered eating ritual. Its construct validity (0.92) and cronbach alpha reliability coefficient $(0.76)$.

\section{Procedure}

At first, permission was taken from the concerned university authorities. After taking permission research participants were selected through convenient sampling. The participants were briefed about the study; they were then requested to fill the Demographic Information Form followed by (EAT-26 questionnaire). Once the data was collected, it was all entered and analyzed on SPSS.

\section{Statistical Analysis}

Descriptive statistics and T-Test were considered for statistical evaluation.

\section{Ethical Consideration}

Data was collected only from those individuals who voluntarily gave their consent to participate in the research. All the participants reserved the right to withdraw at any time

\footnotetext{
${ }^{51}$ Garner, Olmstead, Bohr and Garfinkel, "The eating attitude test: Psychometric features and clinical correlates," Psychological Medicine, (1982): 12, 871-873.
} 
during the administration of the questionnaire. Further they were also informed that their individual information would be protected.

\section{Results}

In total on EAT-26,108 students with (27.0\%) recorded high scores, and 292 students with $(73.0 \%)$ recorded low score.

Table 1

\begin{tabular}{|l|c|}
\hline Demographic Information of Participants & Percentages (\%) \\
\hline Socio-economic Status & 23.8 \\
\hline Upper & 75 \\
Middle & 1.2 \\
Lower & \\
\hline Gender & 50 \\
\hline Male & 50 \\
Female & \\
& \\
\hline BMI & \\
Underweight & 59.5 \\
\hline & 40.5 \\
Male & \\
Female & 44.8 \\
\hline Normal & 55.2 \\
\hline Male & \\
Female & 46.0 \\
\hline Overweight & 54.0 \\
\hline Male & \\
Female & \\
\hline Physical Activity(gym) & 27.5 \\
\hline Yes & 2.0 \\
No & \\
\hline Relation status & \\
\hline Single & \\
Engaged & \\
Married & \\
\hline & \\
\hline & \\
\hline & \\
\hline & \\
\hline & \\
\hline
\end{tabular}


Table 2: Gender differences on demographic variables of Study Participants

\begin{tabular}{|c|c|c|c|c|}
\hline $\begin{array}{c}\text { Demographic } \\
\text { Variables }\end{array}$ & $\begin{array}{c}\text { Total } \\
\mathrm{N}=400(\%)\end{array}$ & $\begin{array}{c}\text { Male } \\
\mathrm{N}=200(\%)\end{array}$ & $\begin{array}{c}\text { Female } \\
\mathrm{N}=200(\%)\end{array}$ & p- value* \\
\hline \multicolumn{5}{|c|}{ Socio-economic Status } \\
\hline Upper & $95(23.8)$ & $36(37.9)$ & $59(62.1)$ & \multirow{3}{*}{$0.02 *$} \\
\hline Middle & $300(75.0)$ & $159(53.0)$ & $141(47.0)$ & \\
\hline Lower & $5(1.2)$ & $5(100.0)$ & $0(0.0)$ & \\
\hline \multicolumn{5}{|l|}{$B M I$} \\
\hline Underweight & $79(19.8)$ & $47(59.5)$ & $32(40.5)$ & \multirow{3}{*}{$0.01 *$} \\
\hline Normal & $259(64.8)$ & $116(44.8)$ & $143(55.2)$ & \\
\hline Overweight & $50(12.5)$ & $27(54.0)$ & $23(46.0)$ & \\
\hline \multicolumn{5}{|c|}{ Physical Activity (gym) } \\
\hline Yes & $290(72.5)$ & $157(54.1)$ & 133(45.9) & \multirow[t]{2}{*}{$0.01 *$} \\
\hline No & $110(27.5)$ & $43(39.1)$ & $67(60.9)$ & \\
\hline \multicolumn{5}{|l|}{ Relation status } \\
\hline Single & $366(91.5)$ & $183(50.0)$ & $183(50.0)$ & \multirow{3}{*}{0.804} \\
\hline Engaged & $26(6.5)$ & $14(53.8)$ & $12(46.2)$ & \\
\hline Married & $8(2.0)$ & $3(37.5)$ & $5(62.5)$ & \\
\hline
\end{tabular}

* Chi-square test: level of significance $<0.05$

In Table 2 both genders were compared on demographic variables, differences were observed on BMI, and socioeconomic status; and physical activity.

Table 3

Independent Sample t-test to depict the variance between male and female university students for disturbed eating attitudes.

\begin{tabular}{|l|l|l|l|l|l|l|l|}
\hline Study Variables & & $\mathrm{N}$ & Mean & Std. Deviation & $\mathrm{t}$ & $\mathrm{df}$ & $\mathrm{p}$-value* \\
\hline
\end{tabular}

Disturbed Eating Attitude

\begin{tabular}{|l|l|l|l|l|l|l|l|}
\hline & Males & 200 & 16.12 & 12.10 & 3.16 & 398 & $0.002^{*}$ \\
\hline & Females & 200 & 12.13 & 11.43 & & & \\
\hline
\end{tabular}

$*$ p-value $<0.05$

Table 3 illustrates a notable difference in the mean and standard marks of disturbed eating attitude among male and female university students. Which further elaborates that 
male university students experience more disturbed eating attitude as compare to female university students.

\section{Discussion}

Permitting to young adults ranging from the age (18 to 25$)$ are increasingly facing serious challenges related to eating approaches, that are impacting not only their development but also their existence. Most of them have transformed their regular eating patterns into faulty ones. ${ }^{52}$ Present exploration was also purposed to explore the disturbed practices of eating among undergraduates. For that reason it was objected to see the differences among men and women studying in university capacities with reference to disturbed approaches of eating. It was expected that female university learners would be carrying more disturbed eating approaches than male university learners. Findings of the present study showed overall problematic eating approaches in $(n=108,27.0 \%)$ students and no problematic eating approach in $(\mathrm{n}=292,73.0 \%)$ students. Further the discrepancy among genders was set up to be statistically significant with $\mathrm{t}$-Test $(\mathrm{t}=3.16, \mathrm{p}<0.002)$ (table 3 ), where EAT-26 mean marks for male learners was (16.12) and for female was (12.13). Results cleared that males found to practice disturbed eating approaches more than females. Finding of the purposed study is constant with the assessment on first year male university found commonly involved in skipping their meals, a number of them reported that they do munching in the middle of mealtimes, but those who were dissatisfied with their bodies were predisposed to cut their meals more ${ }^{53}$ In another observation in India, sixty-six percent of male undergraduates observed to be heavily involved in avoiding their suppertimes, despite of having ample information about its disadvantages, they continued following unhealthy meal skipping behavior. A high nutritive deficiency was found among students with disturbed eating behaviors. ${ }^{54}$ Similarly, it was also observed that in newcomer male undergraduates with faulty eating approaches exhibited less attentiveness compared to males with healthy ways of eating. ${ }^{55}$ Similar results with low education attentiveness in males and unhealthy eating patterns have been testified in another study. ${ }^{56}$ A study in Washington DC, found minor warning signs of disruptive eating attitudes in $(11 \%)$ of male undergraduates. ${ }^{57}$ By the same token, an exploration revealed $(80 \%)$ of male undergraduates wished to have ideal-body and had slight marks of unhealthy eating patterns. ${ }^{58}$ An investigation traced in $(21 \%)$ male as meal skipper with $(20 \%)$ being undernourished, of all these $(6 \%)$ were taking medicines in the place of

\footnotetext{
${ }^{52}$ Mishra and Mukhopadhyay, "Eating and weight concerns among university students and their biocultural correlates: An exploratory study," Journal of Public Health Nutrition, 14(5), 2010, 853-859.

${ }^{53}$ Chugh, "Affluent male and female of Delhi: eating and weight concerns," British Journal of Nutrition, 86 (4), 2001, 535-542.

${ }^{54}$ Pimenta, "Relationship between body image disturbances and eating disorder," Journal of Psychology, 9(4), 2009,1-9.

${ }^{55}$ Kapoor and Aneja, "Nutritional disorders in males and females, "Journal of Nutrition", 29(8), 1992, 969973

${ }^{56}$ Cash, "Body Image: A Handbook of Theory, Research and Clinical Practice,"(The Guildford Press, London, 2004), 52.

${ }^{57}$ Favor, "Food as Foe:Nutrition and Eating Disorders," (Courtesy of the National Academic Press, Washington, DC, 2007), 56 .

${ }^{58}$ Eagles and Johnston, "Increasing incidence of eating problems in the university population of northeast Scotland," American Journal of Psychiatry,152(9), 1995, 1266-1271.
} 
food. ${ }^{59}$ Correspondingly a survey illustrated that male students with unhealthy eating practices were found to have remarkable drops in their body-weight $(\text { BMI }>11.5)^{60}$ which itself is a negative practice. Similar results found in $(0.4 \%)$ university males in Himalaya, North India. ${ }^{61}$

Bearing in mind about the causative elements of unhealthy eating attempts in university students, particularly in males, an influence of friends, batch mates, social broadcasting and pressures to meet the societal demands are taken as major reasons of their disturbed eating attitudes. A study in Lahore identified concerns towards physical appearance, urge to fulfill societal demands to look perfect and dissatisfaction with bulge and weight in males of (18-25) years of age. ${ }^{62}$ A study in Singapore reported $(45.1 \%)$ of males with faulty eating habits in the course of 2002-2010 conveyed, being exposed to communal pressure and mocked by colleagues and friends, as a causal factor of their unhealthy eating behaviors. ${ }^{63}$ Likewise in another research (279) male undergraduates reported media exposure and societal pressure as a reason of their disturbed eating habits. ${ }^{64}$ One more examination on male learners validated straight effect of friends and classmates on their food choices and eating patterns. ${ }^{65}$

In (table 2) comparing both gender on BMI, physical activity and socioeconomic status, $(59.5 \%)$ of males found to be underweight as compare to $(40.5 \%)$ females. A Malaysian study in this direction also showed similar results. ${ }^{66}$ There were $(72.5 \%)$ of males identified as spending time in physical activities than (27.5\%) females. The less availability of gyms and fitness centers for females could be the reason. Moreover, overall $(75 \%)$ of research participants belonged to middle class, among which (53.0\%) were males and $(47.0 \%)$ were females. A research in direction to faulty eating patterns suggested that young people belonging to middle and upper socioeconomic status are more in practice of unhealthy attempts of eating. ${ }^{67}$

Hence results of current research aided and delivered the understanding that disturbed eating approaches are not only limited to females, it is now prevailing into the males as well. According to an exploration in Pakistan, males in this country are gradually

${ }^{59}$ Crawley and Shergill-Bonner, "The nutrient and food intake habits in university students in UK," Journal of Human Nutrition and Dietetics, 8 (1), 1995, 25-34.

${ }^{60}$ Lask, "Early-onset of eating related pathologies", Journal of Psychology and Psychiatry, 33(1), 2002, 281300 .

${ }^{61}$ Bhugra and Bhui, "Problematic eating and socio-centric values in undergraduates," Social Psychiatry and Psychiatric Epidemiology, (October, 2000): 35, 86-93.

${ }^{62}$ Choudary, "Body dissatisfaction and eating attitudes in slimming and fitness gyms in Lahore: A crosscultural study". Pakistan Journal of Psychological Research, 8(3), 2000, 217-224.

${ }^{63}$ Lee, "Pathological Eating in Singapore: a nine-year retrospective study". Medical Journal of Singapore. 46 (6), 2010, 275-81.

${ }^{64}$ Baker, Little and Brownell, "Predicting adult eating and activity behaviors: The role of social norms and personal agency," Health Psychology, (July, 2004): 22, 189-198.

${ }^{65}$ Adair, "Dramatic rise in overweight and obesity in young Malaysian adult". Obesity Research, (2004):12, $1335-1341$

${ }^{66}$ Monge-Rojas, Nũnez, Garita and Chen-Mok, "Psychosocial aspects of Costa Rican adolescents' eating and physical activity patterns," Journal of Adolescent Health, 31(2), 2002, 212-219.

${ }^{67}$ Abell and Richards, "The relationship between body shape satisfaction and self-esteem: An investigation of gender and class differences", Journal of Youth and Adolescents, 25(5), 1996, 691-703. 
increasing the odd eating habits ${ }^{68}$, yet more work is required to understand the impacting factors of odd eating patterns in males.

\section{Conclusion and Implication}

Thus it can be concluded from the result of current study that male undergraduates were found to be more prone towards disturbed eating approaches as compared to female undergraduates. Outcomes of present exploration can benefit the guidance counselor, general public, students, parents and academic institutions in handling the disturbed practices of eating, especially in preventing it from the severity level. Further academia can play a vital role for inducing healthy activity among their undergraduates'. Campaigns on media about the welfares of healthy eating and its benefits can play a beneficial role. Awareness programs for parents to promote healthy eating patterns in their children can be very essential. Mental health practitioners through workshops and seminars may help in preventing disturbed eating attitudes. In the same way understanding of unsafe aspects is very important for prime and advanced protection. Further prevention methods, tactics and policies for reducing the severity levels of unhealthy eating practices in student population, should be operative and directed on the features that are linked to the development of disturbed approaches of eating. However the outcomes of present search cannot be generalized, more researches in this area are still required and may well be essential in identifying other important factors and figures. Investigations to understand the effects of cultural diversity on eating approaches are essentially desirable

\section{Limitation}

The result of the search was based on only four hundred participants, which may have restrained the study result from making it a sweeping statement. Besides that more investigations can be steered to scan this variable in other mental and emotional areas. EAT-26 is a screening tool for identifying unhealthy eating behavior; proper diagnostic tools must be in-cooperated for better understanding of disturbed eating among the population.

\section{Bibliography}

Adair, "Dramatic rise in overweight and obesity in young Malaysian adult". Obesity Research, 12, 2004:1335-1341.

Alvarenga, “Disordered Eating Attitude”. Percept Mot Skills, 110(2), 2010, 379-395.

Apter and Abu Shah, "Cultural effects on eating attitudes in Israeli sub-populations and hospitalized anorectics." Genetic, Social, and General Psychology Monographs, 2004:120, 83-99.

${ }^{68}$ Ashfaq, "Gender difference in physical fitness, life style, body shape satisfaction, and body figure preferences, Pakistan Journal of Psychological Research, 23(1), 2008, 34-35. 
Abell and Richards, "The relationship between body shape satisfaction and self-esteem: An investigation of gender and class differences", Journal of Youth and Adolescents, 25(5), 1996, 691-703.

Ashfaq, "Gender difference in physical fitness, life style, body shape satisfaction, and body figure preferences", Pakistan Journal of Psychological Research, 23(1), 2008, 3435 .

Brandsma and Lynn, "Eating disorders across the lifespan," Journal of Women \& Aging, 19(11), 2007, 155-172.

Pimenta, "Relationship between body image disturbances and incidence of depression," Journal of Psychology, 9(4), 2009,1-9.

Bhugra and Bhui, "Problematic eating and socio-centric values in undergraduates," Social Psychiatry and Psychiatric Epidemiology, 35, 200: 86-93.

Baker, Little and Brownell, "Predicting adult eating and activity behaviors: The role of social norms and personal agency," Health Psychology, 22, 2004:189-198.

Balhara, Yadav, Arya, Mathur and Kataria, "A cross-sectional study of body shape and eating attitude among Indian female healthcare students". International Journal of Psychiatry in Medicine, 43(4), 2012: 309-323 https://doi.org/10.2190/PM.43.4.b

Chan MF, Ho A, Day MC. Investigating the knowledge, attitudes and practice patterns of operating room staff towards standard and transmission-based precautions: results of a cluster analysis. J Clin Nurs ,17(8), 2008:1051-1062. doi: 10.1111/j.13652702.2007.01998.

Conley and Amanda, "Weight overestimation as an indicator of disordered eating behaviors among young women in the United States," International Journal of Eating Disorders, 40(5), 2007, 441-445.

Coker and Austin, "The health and health care of adolescents". Health Science, 31, 2010: 457-477.

Chugh, "Affluent male and female of Delhi: eating and weight concerns," British Journal of Nutrition, 86 (4), 2001, 535-542.

Cash, "Body Image: A Handbook of Theory, Research and Clinical Practice,"(The Guildford Press, London, 2004), 52.

Crawley and Shergill-Bonner, "The nutrient and food intake habits in university students in UK," Journal of Human Nutrition and Dietetics, 8 (1), 1995, 25-34.

Choudary, "Body dissatisfaction and eating attitudes in slimming and fitness gyms in Lahore: A cross-cultural study". Pakistan Journal of Psychological Research, 8(3), 2000, 217-224. 
Davis, "Body and self-esteem ratings as a prelude to dieting and exercise among Chinese men and women", International Journal of Eating Disorders, 23(4), 1998, 99-102.

Eapen, "Disordered eating attitudes and symptomatology among adolescent girls in the United Arab Emirates," Eating Behaviors, 2006:7, 53-60.

Eagles and Johnston, "Increasing incidence of eating problems in the university population of northeast Scotland," American Journal of Psychiatry,152(9), 1995, 12661271.

Fischer, "Comorbidity and high-risk behaviors in treatment- seeking adolescents with bulimia nervosa," International Journal of Eating Disorders, 40(8), 2007, 751-753.

Field and Camargo, "Peer, parent, and media influences on the development of weight concerns and frequent dieting among girls and boys," International Journal of Eating Disorders, 107(1), 2001, 54-60.

Favor, "Food as Foe:Nutrition and Eating Disorders," (Courtesy of the National Academic Press, Washington, DC, 2007), 56.

Gustafson-Larson and Terry, "Weight-related behaviors and concerns in males and females," Journal of American Dietetic Association, 92(7), 1992, 818-822.

Garner, Olmstead, Bohr and Garfinkel, "The eating attitude test: Psychometric features and clinical correlates," Psychological Medicine, 12, 1982: 871-873.

Human Nutrition, Nutrition Country Profile, Lebanon.

http://www.fao.org/ag/agn/nutrition/lbn_en.stm

Harrison ME, Norris ML, Obeid N, et al. Systematic review of the effects of family meal frequency on psychosocial outcomes in youth". Can Fam Physician61(2), 2015,96-106.

Harrison, "Ourselves, our bodies: media-ideal, self discrepancies, and eating disorder symptomatology," Journal of Social and Clinical Psychology, 20(3), 2001, 289-323.

Hill and Franklin, "Peer pressure and dieting: Investigating the transmission of weight control," British Journal of Clinical Psychology,37(1), 1998, 3-13.

Jina Tanton, Lorna, Dodd, Lorayne Woodfield and Mzwandile Mabhala, "Eating Behaviors of British University Students: A Cluster Analysis on a Neglected Issue", Advances in Preventive Medicine, Vol 2015, Article ID 639239, 8 pages, http://dx.doi.org/10.1155/2015/639239

Kugu, Akyuz and Izgic, "The prevalence of eating disorders among university students and the relationship with some individual characteristics," Australian and New Zealand Journal of Psychiatry, 40(3), 2006 129-135. 
Kapoor and Aneja, "Nutritional disorders in males and females," Journal of Nutrition ", 29(8), 1992, 969-973.

Lorenzo and Lavori, "Eating attitudes in high school students in the Philippines: A preliminary study," Journal of Eating Disorders, 7(3), 2002, 202-209.

Luo and Parish, "A population-based study of eating concerns among urban Chinese adults," Journal of Psychology, 2 (4), 2006, 333-345.

Lowery and Sarah, "Body image, self-esteem, and health-related behaviors among male and female first-year university students," Journal of Eating Disorders, 46(6), 2005, 612623.

Lee, Pathologic eating in Taiwan undergraduates, International Journal of Eating Disorder, 40(3), 2007, 227-31.

Lask, "Early-onset of eating related pathologies", Journal of Psychology and Psychiatry, 33(1), 2002, 281-300.

Lock, "Pathological Eating in Singapore: a nine-year retrospective study". Medical Journal of Singapore. 46 (6), 2010, 275-81.

Memon, Adil,Umar, Naeem and Adnan, "Eating disorders in medical students of Karachi, Pakistan”. BMC Research Notes. 5, 2012, 84 doi: 10.1186/1756-0500-5-84

Mishra and Mukhopadhyay, "Eating and weight concerns among university students and their biocultural correlates: An exploratory study," Journal of Public Health Nutrition, 14(5), 2010, 853-859.

Monge-Rojas, Nũnez, Garita and Chen-Mok, "Psychosocial aspects of Costa Rican adolescents' eating and physical activity patterns," Journal of Adolescent Health, 31(2), 2002, 212-219.

Madanat, Lindsay and Campbell, "Young urban women and the nutrition transition in Jordan”, Public Health Nutrition,14(4), 2011, 599-604.4

Maor and Sayag, "Eating attitudes among youth," Turkish Medical Association Journal, $8(9), 2006,627-629$.

Mitchell and Eckert, "Scope and significance of eating disorders," Journal of Consulting and Clinical Psychology, 55, 1987: 628-634.

Nunes, Barros, Anselmo, Camey and Mari, "Prevalence of abnormal eating behavior and inappropriate methods of weight control in young women from Brazil: a population based study". Eat Weight Disord, 2003, 8:100-6. 
Ousley, "Fat talk among undergraduate students: How university students communicate regarding food and body weight, shape \& appearance," Journal of Eating Disorders, 16(8), 2008, 73-84.

Ong and Tsoi, "A clinical and psychosocial study of seven cases of anorexia nervosa in Singapore. Singapore Medical Journal, 23, 2000: 255-61.

Pimenta, "Relationship between body image disturbances and eating disorder," Journal of Psychology, 9(4), 2009,1-9.

Philpott, "More than mere vanity," Guidance and Counseling,14,1998: 28-39.

Rhee and Park, "Epidemiology of eating disorder symptoms in the Korean general population using a Korean version of the EAT": Eat Weight Disorder, 4, 2006:153-61.

Sampei, Sigulem, Novo, Juliano and Colugnati,"Eating attitudes and body image in ethnic Japanese females". Journal of Eating Behavior, 85(2), 2009,122-128.

Starkey, Johnson-Down and Gray-Donald, "Food habits of Canadians: comparison of intakes in adults and adolescents to Canada's food guide to healthy eating", Can J Diet Pract, 62(2), 2001, 61-9.

Sharma, "Trends in the intake of ready-to-eat food among young students in Nepal," Journal of Psychology,16(5), 1998, 21-22.

Shin HS, Valente TW, Riggs NR, et al, "The interaction of social networks and child obesity prevention program effects: the pathways trial. Obesity", 22(6), 2014,1520-1526. doi: 10.1002/oby.20731

Suresh and Fernandez,"Eating disorders in India". Indian Journal of Psychiatry, $37(1), 2000,26-30$

Suhail, K and Zaib-u-Nisa, "Prevalence of eating disorders in Pakistan: Relationship with depression and body shape". Eat Weight Disorder, 7(2), 2012, 131-8.

Tsai, "Survey on eating related thoughts, behaviors and dietary intake in female undergraduates in Taiwan, Asia Pacific Journal of Clinical Nutrition, 20, 2011:196-205.

Trautmann and Julie, "Body Dissatisfaction, Bulimic symptoms, and clothing practices among males and females," The Journal of Psychology, 141(5), 2007, 485-498.

Thompson, "Body shape, eating disorders, and obesity in youth", (Washington DC, US, 2002)

Tiggemann and Pickering, "Role of television in men and women's body dissatisfaction," International Journal of Eating Disorders,” 20(2), 1996, 199-203. 
Ung, "Eating disorders in Singapore: A Review". Singapore Medical Journal. 32, 2003, $19-24$.

Upadhyah, Misra, Parchwani and Maheria, "Prevalence and risk factors for eating disorders in Indian adolescent females". National Journal of Physiology, Pharmacy \& Pharmacology, 4(2), 2014:153-157 DOI: 10.5455/njppp.2014.4.041220131

Velde SJ, Chin APaw MJ, De Bourdeaudhuij I, et al, "Parents and friends both matter: simultaneous and interactive influences of parents and friends on European schoolchildren's energy balance-related behaviours - the ENERGY cross-sectional study. Int J Behav Nutr Phys Act. 11, 2014:82. doi: 10.1186/1479-5868-11-82

Verstraeten R, Van Royen K, Ochoa-Avilés A, et al, “A conceptual framework for healthy eating behavior in Ecuadorian adolescents: a qualitative study". PLoS One. 9(1), 2014:871-83. doi: 10.1371/journal.pone.0087183

Vaida, "Prevalence of media exposure and its impact among urban students," The International Journal of Science, 2(3), 2013, 353-359.

Wharton and Christopher, "Weight loss practices and body weight perceptions among US university students," Journal of American College Health, 56(5), 2008, 579-584.

Wilson and Jan, "The relative contributions of subjective and objective measures of body shape and size to body image and disordered eating in women," Journal of Molecular Biology, 2(3), 2005, 233-47.

Yahia, Achkar, Abdallah and Rizk, "Eating habits and obesity among Lebanese university students",Nutrition Journal, 7, 2008:32, https://doi.org/10.1186/1475-2891-732

Yamazaki, "Prevalence of eating disorders in a geographically defined area in Japan. International Journal of Eating Disorder, 28(2), 2000, 173-80. 